\title{
The Impacts of Various Ratios of Different Hydrocolloids and Surfactants on Quality Characteristics of Corn Starch Based Gluten-free Bread
}

\author{
H. DIZLEK ${ }^{1 *}$ and M.S. OzER ${ }^{2}$ \\ ${ }^{1}$ Department of Food Engineering, Faculty of Engineering, Osmaniye Korkut Ata University, \\ 80000 Osmaniye, Turkey \\ ${ }^{2}$ Department of Food Engineering, Faculty of Agriculture, Cukurova University, 01330 Adana, Turkey \\ (Received 6 May 2015; Accepted 20 October 2015; \\ Communicated by X.F. Zhang and F. Békés)
}

In this study, the effects of 18 different additive formulas constituted with xanthan and hydroxypropylmethylcellulose (HPMC) gums (hydrocolloids) were examined in the manufacture of corn starch based gluten-free bread. The additives used as alone or in combinations in the bread manufacture. It was also added with mono- and diglyceride based gel preparations and diacetyl tartaric acid esters of mono- and diglycerides for improving glutenfree bread characteristics. The volumes and softness of the breads have been measured as maximum when HPMC was used alone in increasing order from 1 to $2 \%$. While HPMC gum improved the volume and softness of bread more than Xanthan gum, Xanthan gum improved the grain structure of crumb more than HPMC. In general, these hydrocolloids gave a good quality of bread in terms of moisture content, grain structure and Neumann baking coefficient values, when they were used with combinations rather than being used individually. Addition of surfactant to all combinations always enhanced the grain structure of bread. In contrast, it either worsened or did not change the volume and softness of the bread.

Keywords: corn starch, gluten-free bread, hydrocolloid, surfactant, bread quality

\section{Introduction}

Celiac is a type of disease characterized by an immune system-induced intestinal disorder which caused by the interaction between the genetic and environmental factors. It is a malabsorption syndrome that appears in susceptible individuals after the intake of gluten containing foods (Holtmeier and Caspary 2006). The disease is caused by consuming of prolamine contained in the gluten protein complex in some cereals such as wheat, barley, rye, oat, etc. These are used frequently in the diet (Gallagher et al. 2004; Ciclitira et al. 2005; Turabi et al. 2008). Alone method for the Celiac patients is giving a gluten-free diet (Katina et al. 2005; Gobbetti et al. 2007). In gluten-free diet, it is prohibited to eat any food that contains wheat, barley, rye and oat flour; however, rice, corn and other cereal products that do not contain gluten as well as such food as meat, fish and vegetables can

\footnotetext{
*Corresponding author; E-mail: hdizlek@osmaniye.edu.tr; Phone: +90 328 8271000/3404
} 
be consumed to an extent as desired (Gallagher et al. 2004; López et al. 2004). The fact is however that the gluten-free diet issue is much more complex firstly because of the fact that people suffering in Celiac disease are the far minority of those who have health problems (allergy, IBS etc.) caused by cereal consumption and secondly because - based on recent surveys $-70 \%$ of the people on gluten-free diet believe that it is a healthy lifestyle choice or because it is trendy. Although there are currently various alternative ready-toeat products for the purpose of meeting the nutritional requirements of the Celiac patients, especially those Celiac patients who live in the rural areas have serious troubles as these products are expensive and they are not easily accessible everywhere (Turabi et al. 2008; O'neill 2010).

Gluten is the most essential element that has very significant impacts on the technological characteristics of such products as bread, cake and pasta. Those are made of intermediate products originated from wheat and determine the quality of such products (Shewry et al. 1997). Manufacturing other products, particularly bread making using some food additives as a substitute for gluten is considered among the matters that have been significantly emphasized by the food science and technology in recent years (Farrell and Kelly 2001; Turabi et al. 2008; Sciarini et al. 2010; Torbica et al. 2010). It was reported for gluten-free food that finished products with improved quality can be manufactured using modified starches, hydrocolloids, some herbal and animal protein sources and surfactants (Gallagher et al. 2004; Yaseen et al. 2005; Marco and Rosell 2008; Demirkesen et al. 2014) and that especially hydrocolloids can be successfully employed in manufacturing gluten-free bakery products to meet the functions of gluten to some extent (Lazaridou et al. 2007). Hydrocolloids improve the textural properties of the food in which they are used, retard the retro gradation of starch, improve the retention of moisture in food and maintain the general quality of the product during the storage (Stauffer 1990; Rosell et al. 2001). Surfactants cause a decrease in the specific weight of the dough, maintain the stable air in dough, enable the dough to have a uniform and shiny appearance, increase the specific volume and eating quality of the finished product, retard its staling (extend the shelf-life), improve the structural characteristics of the product and increase the attraction of the bakery products with all the above-mentioned characteristics (Birnbaum 1978; Ebeler and Walker 1984).

Corn and rice flour and starch are frequently used in manufacturing gluten-free bakery products (López et al. 2004; Turabi et al. 2008) which are usually characterized with poor texture, low and insufficient volume, fast staling and easy crumbling (Toufeili et al. 1994; Gallagher et al. 2003; Mahmoud et al. 2013). Although celiac patients are not happy with the products, most of the gluten-free products must be inevitably eaten by the celiac patients.

In this research, it was aimed to study the effects of use of some hydrocolloids alone or in combinations with surfactant preparations on the quality of gluten-free bread with such quality that can be satisfactorily consumed by the celiac patients. 


\section{Materials and Methods}

\section{Materials}

In this research, the corn starch supplied from the Amylum Starch Co. (Adana, Turkey), Asuka-brand xanthan gum supplied from the Asuka Trading Co. Ltd. (Hong Kong, China), hydroxypropylmethylcellulose (HPMC) manufactured by the Dow Chemical Co. (Midland, Michigan, USA), Admul 1982-brand diacetyl tartaric acid esters of mono- and diglycerides (DATEM) manufactured by the Quest International Inc. (Neu-Isenburg, Germany), food-grade L-ascorbic acid (L-AA) manufactured by the BASF Co. (Ludwigshafen, Germany), enzymatically inactive non-fat soybean flour manufactured by the Turksoy Co. (Izmir, Turkey), baker's yeast (pressed fresh yeast) manufactured by the LeSaffree-Ozmaya Co. (Adana, Turkey), potable water supplied within the campus of Cukurova University, and granulated refined salt, granulated sugar and vegetable oil supplied from local groceries were used in gluten-free bread making.

Rikevita brand pure mono- and diglycerides in powder form (E471, Rikevita Sdn Bhd., Johor Bahru, Malaysia) were used in surfactant preparation used for some bread formulations. It was observed during the preliminary experiments that E471 is not fully dissolved when it is added in a powder form into dough formulation, and therefore, it is not uniformly distributed. Thus, E471 additive used in the research was turned into a preparation in gel form using the ingredients as listed in Table $\mathrm{S} 1 *$ at specified amounts and by applying the procedure steps as indicated in Fig. S1. To this end, food-grade monopropylene glycol, glycerine and potassium stearate (Yilmaz Kimya Co., Istanbul, Turkey) were used. All of the additives used in this study are safe for human health (International Food Information Council [IFIC] Foundation and United States Food and Drug Administration [FDA] 2010; United States Department of Agriculture Food Safety and Inspection Service 2015) (Table S1 and Fig. S1).

In the research, Kitchen Aid's "KSM45" model electric mixer (KitchenAid Inc., St. Joseph, Michigan, USA) and baking pans in which specified by American Association of Cereal Chemists International (AACCI) Method 10-10B (AACCI 2000) were used. The fermentation procedure was carried out in the fermentation chamber made of heatinsulated material and equipped with heating system and steam unit. Baking was carried out in a "Wiesheu, EBO 1-64R" model stone floor oven.

\section{Methods}

Some preliminary experiments were performed during the initial phase of the research. Thus it was aimed to determine the appropriate values and practices for some basic procedures to be applied during the main experiments. As there could not be taken measurements from many bread samples manufactured as a result of the preliminary experiments, these were not reflected to the content of the study. In cases where the hydrocolloids were not used at all, or were used at a level of $0.5 \%$ during the preliminary experiments, no

\footnotetext{
* Further details about the Electronic Supplementary Material (ESM) can be found at the end of the article.
} 
enough baking was observed in the dough. Therefore, no bread samples could be produced, which belongs to the control sample (hydrocolloid-free bread), and thus, no measurements could be taken. With the use of hydrocolloids by $1 \%$ and above in bread making, such breads which can be baked and are consumable with improved product characteristics could be manufactured.

In the study, the impacts of different combinations of hydrocolloids and surfactants on the bread quality in gluten-free bread making were examined. To this end, in bread making, $5 \%$ sugar, $4 \%$ yeast, $4 \%$ oil, $3 \%$ soybean flour, $1.6 \%$ salt, $75 \mathrm{mg} / \mathrm{kg} \mathrm{L-AA}$ as fixed ingredients on the starch basis and $410 \mathrm{~mL}$ water per formulation (as a fixed ingredient in each dough formulation; $350 \mathrm{~g}$ starch, $17.5 \mathrm{~g}$ sugar, $14 \mathrm{~g}$ yeast, $14 \mathrm{~mL}$ oil, $10.5 \mathrm{~g}$ soybean flour, $5.6 \mathrm{~g}$ salt, $0.02625 \mathrm{~g} \mathrm{~L}-\mathrm{AA}$ and $410 \mathrm{~mL}$ water) were used. Xanthan gum, HPMC gum and surfactant were used as variable ingredients. In the research, the levels of use of the variable ingredients on the basis of starch (experimental design) are shown in Table S2. In formulations where the surfactants are used (samples with even formulation number), of surfactant rate of $3.36 \%$ on the basis of starch, $2.86 \%(10 \mathrm{~g})$ consisted of the surfactant preparation in gel form and the remaining $0.5 \%$ consisted of $(1.75 \mathrm{~g})$ DATEM.

Bread making experiments with 18 different formulations as shown in Table S2 were carried out three times, and to this end, 54 dry ingredient bags were prepared in total. In these bags used in the experiments, there were fixed amount of ingredients in dough form, starch, sugar, soybean flour and L-AA, while DATEM was included in these bags in addition to the foregoing ingredients for the formulations where surfactants were used. In preparation of the bags for dry ingredients used in the research, $250 \mathrm{~g}$ starch was weighed for each bag at first and this was followed by the addition of other fixed dry ingredients in the bags on the basis of $350 \mathrm{~g}$ starch. After the additives (Xanthan and HPMC gums) which were used in different compositions and ratios in each experiments had been individually weighed on a precision scale, they were made uniform by being mixed with $100 \mathrm{~g}$ starch in a mixer at low speed $(65 \mathrm{rev} / \mathrm{min})$ for $15 \mathrm{~s}$. Then this mixture was uniformly mixed with the previously prepared starch and other fixed dry ingredients mixture and they were stored at suitable conditions in the laboratory until they were used in bread making experiments. In the research, the procedure followed for bread making is diagrammatized in Fig. S2.

Mixing, fermentation and baking periods as well as fermentation and baking temperatures applied in the research were determined as a result of the preliminary experiments.

\section{Bread analysis}

Loaf volume of breads was measured by rapeseed displacement method in $\mathrm{cm}^{3}$ (AACCI 2000). The volume of the bread made from $100 \mathrm{~g}$ starch on the basis of $14 \%$ moisture was calculated as the volume yield (Gul et al. 2009). For the purpose of determining the volume yield of bread samples, the dough formula and starch content in the formula were taken into consideration and the calculation was made by proportion. Moisture content of breads was determined with the help of the drying oven and final weighing procedure was performed after the bread samples had reached a certain weight (AACCI 2000). Crumb- 
grain structure was evaluated visually and judged according to the Dallman scale 1-8 with higher Dallman scale numbers indicating smaller pores and more dense structure in bread (TSE 1987). SUR penetrometer PNR 6 (SUR Berlin, Germany) with $200 \mathrm{~g}$ of total test weight was used to determine the crumb firmness (penetrometer values) of the finished product as indicated by Ozer and Altan (1995). In determining the crumbling value of breads, the bread samples were precision weighed $(\mathrm{g})$ on an appropriate scale at first and then they were cut into $1 \mathrm{~cm}$ slices with the help of a "Bosch" electrical knife. All bread slices obtained after cutting were weighed and the crumbling values of bread samples were calculated by proportioning to the initial bread weight. In calculating the Neumann Baking Coefficient (NBC) values of the bread samples, the pore scale (Table S3) developed by Dallman was used (Uluoz 1965).

NBC value developed by Neumann was calculated by taking the volume and pore factors into account (Neumann 1929):

$$
\mathrm{NBC}=\frac{\text { Volume factor } \times \text { Pore factor }}{100}
$$

where the volume of bread made of $100 \mathrm{~g}$ starch is $400 \mathrm{~cm}^{3}$, the volume factor was accepted as 100, and calculated by adding 100 to the half of the amount higher than $400 \mathrm{~cm}^{3}$ for the breads with a volume higher than $400 \mathrm{~cm}^{3}$ (Uluoz 1965). Pore factor was determined using the values as provided in TS 5000 (TSE 1987) and Table S3. Moisture content, crumb firmness and crumbling were measured within 6 and $24 \mathrm{~h}$ later than bread samples were removed from the oven and other analyses were conducted within $6 \mathrm{~h}$ later than the breads were removed from the oven.

\section{Statistical analysis}

All experiments were carried out in three replicates. Analyses of variance (ANOVA) were conducted by using the Statistical Analysis System procedures (SAS Institute, Cary, NC, USA). When a significant difference was found between the treatments, Duncan's multiple range tests were performed to determine the differences among the mean values $(P<0.01)$.

\section{Results}

Average volume yields, pore and NBC values, moisture content, crumb softness and crumbling values of breads samples were given in Table S4. Different hydrocolloids and their different ratios as well as whether surfactants were used had a significant impact on the volume yield values of the breads $(P<0.01)$.

The best result in terms of volume yield was found in the bread sample $\left(912 \mathrm{~cm}^{3} /\right.$ $100 \mathrm{~g}$ starch) made on the basis of the formula where HPMC was used at a level of $2 \%$ (Table S4). The volume yield achieved when the same level of xanthan gum was used was $550 \mathrm{~cm}^{3} / 100 \mathrm{~g}$ starch (formula 5). When the volume yield values were examined together 
with all the use levels of the gums as taken into consideration during the experiment $(1 \%$, $1.5 \%$ and $2 \%$ ), it was concluded that HPMC gum has an apparent superiority over xanthan gum. The highest volume yield achieved when both hydrocolloids $\left(751 \mathrm{~cm}^{3} / 100 \mathrm{~g}\right.$ starch - formula 17) were used together was much higher than that was achieved with the breads where xanthan gum was used alone; however, there could not be achieved the result of the breads where HPMC gum was used.

The pore values of bread samples vary in a wide range between 1.6 (formula 9) and 7.3 points (formulas 2 and 6). The samples with the best crumb-grain structure are the samples no 2, 6 and 18 which include surfactant and xanthan gum in their composition (7.3, 7.3 and 7 point, respectively), and the samples with the worst crumb-grain structure are the samples no 9, 11 and 7 which include only HPMC gum in their composition $(1.6,3$ and 3 point, respectively). The factors studied hereunder have a significant $(P<0.01)$ impact on the pore structure of bread samples (Table S4).

NBC value of the bread made using the formula 17 is significantly higher than the value of other samples (Table S4). This is because both volume yield $\left(751 \mathrm{~cm}^{3} / 100 \mathrm{~g}\right.$ starch) and crumb-grain structure (6.6 point) of the relevant sample are high. The additives and their ratios have a significant $(P<0.01)$ effect on the NBC values of breads.

In terms of NBC value, the best results were usually achieved from the studies where both hydrocolloids were used together in its composition but surfactants were not used (formulas 17, 13 and 15). NBC values of the breads where HPMC gum was used alone are better than the breads where xanthan gum was used alone. In general, NBC values increased in parallel to the increase in the usage ratio of gums (Table S4).

The moisture content of breads (Table S4) at the $6^{\text {th }} \mathrm{h}$ is different for the first sample (formula $1 ; 36.22 \%$ ) than the last sample (formula 18; 39.36\%). The breads with the highest moisture content are made using the formulas 18,17, 16, 15 and 14, while those with the lowest moisture content are made using formulas 1, 8, 2, 7 and 3.

After a storage period of $18 \mathrm{~h}$, the moisture content of bread samples slightly decreased. This suggests that the additives used are effective in retention of the moisture content of breads. After a storage period of $24 \mathrm{~h}$, the moisture content of breads decreased at various rates ranging between $0.1 \%$ (formula 6 ) and $1 \%$ (formula 13 ) compared to the $6^{\text {th }} \mathrm{h}$. The moisture content of breads in 1 day after they had been removed from the oven did not statistically decrease - in general - compared to the $6^{\text {th }} \mathrm{h}$ following their removal from the oven $\left(P>0.01\right.$; in measurements at two-hour intervals $\left[6^{\text {th }}\right.$ and $\left.24^{\text {th }}\right]$, the moisture content of the breads were designated with the same letter. There was only a limited change in samples 1, 12 and 15). There was not seen any significant impact of a specific type of gum on the moisture loss in the breads caused by the storing. It was concluded that the procedures applied in the experiments had a clear and significant $(P<0.01)$ effect on the moisture content of the breads.

While the highest penetrometer values of breads for the measurements at the $6^{\text {th }} \mathrm{h}$ were seen in the formulas 11, 9 and 7 (126.2, 118.7 and 109 1/10 mm, respectively); the lowest penetrometer values were observed in the formulas 1,8 and $5(39.3,48$ and $51.81 / 10$ $\mathrm{mm}$, respectively). The formulas where the HPMC gum was used alone (without surfactant) had the best values in terms of the crumb softness (Table S4). 
It was observed that the values at the $24^{\text {th }} \mathrm{h}$ are consistent with those at the $6^{\text {th }} \mathrm{h}$ (Table S4). After a storage period of $18 \mathrm{~h}$, the crumb softness values of the breads decreased at a rate ranging between $48 \%$ (formula 17 ) - 76\% (formula 14 ).

In the breads which contains only gum in their composition as an additive (without surfactant), the penetrometer values of bread increased, as the level of hydrocolloid increased. However, this increase was found statistically insignificant $(P>0.01)$. The use of surfactant in the experiments where xanthan gum was used alone increased the crumb softness of the breads (first six formulas) and the use of surfactant in the samples where HPMC gum was used alone caused a significant decrease on the crumb softness values of the breads $(P<0.01)$. In the formulations where both gums are used together, the use of surfactant did not improve the crumb softness values of the breads $(P>0.01)$. The impact of the additives and their ratios on the crumb softness of the breads were found to be significant $(P<0.01)$.

There is no statistical difference $(P>0.01)$ between crumbling values of the breads, especially depending on the high differences between the parallel measurements in some bread samples (Table S4). In general, the breads made of HPMC gum crumble much more than the breads made of the xanthan gum do. As expected, usually after storing, crumbling value of bread samples decreased - except for 2 formulas. For the formula 3 , after a storage period of $18 \mathrm{~h}$, crumbling value of the bread samples increased, while it remained almost the same for the formula 5. It was considered that crumbling decreased (at the $24^{\text {th }} \mathrm{h}$ ) due to the migration of moisture between the crumb and crust after storing. In the all of the breads, crumbling value remained below 1\%. Although there were considerable differences in places between the samples in terms of crumbling values, there was no statistical difference $(P>0.01)$.

\section{Discussion}

In the study, the use of surfactants did not work in terms of increased volume and they caused a significant $(P<0.01)$ decrease in the volume yields of the breads made using HPMC and HPMC and xanthan gum. The findings of this study are consistent with the findings of those researchers reporting that HPMC gum increases the bread volume much more than other gums and enhances softness (Bell 1990; Rosell et al. 2001; Shin et al. 2013).

In the comparison of the breads made using both hydrocolloids in terms of their crumbgrain structure, use of the xanthan gum alone offers a significantly better improvement in the pore structure of breads than the use of the HPMC gum alone. It was further found that pore structure of the breads where both gums were used together (formulas 13, 15 and 17) is better than the breads where the gums are used alone. In the experiments carried out with the same gum, no significant $(P>0.01)$ impact of the differences in gum ratios was seen on the pore structure of the bread samples. As expected, adding surfactants to the dough formula significantly $(P<0.01)$ improved the pore structure of the breads.

In the study, it was observed that there were cracks especially within the areas close to the crust of the breads, which only consist of HPMC (the pore structure of bread was deteriorated in the locations where these cracks are seen), so these breads had achieved 
low scores (Table S4). The lower elasticity of the HPMC gum compared to the xanthan gum at baking conditions had an impact on such cracks (Lazaridou et al. 2007). Adding surfactants to dough formulations consisting of HPMC gum significantly $(P<0.01)$ improved bread crumb-grain structure.

It was reported that the NBC value should be minimum 100 for high-quality bread (Uluoz 1965). In the study, for 15 of the breads made using 18 different formulations, NBC values were found to be higher than 100 (Table S4). On the other hand, the breads made using formulas 1, 3 and 8 were found to have NBC values lower than 100 .

The bread samples with the highest moisture content are achieved using the formulations where the gums are used in combinations and that the moisture content of breads increase in parallel with the increase of gum level on the basis of starch both the combination formulas and the formulations where the gums are used alone. Furthermore, the moisture content of the breads containing HPMC gum is higher than those containing xanthan gum and that water retention capacity of the breads improve with the combined use of both gums. The findings obtained in this stage of the study are consistent with the reports of Stauffer (1990), Gallagher et al. (2004) and with the findings of Rosell et al. (2001), Gujral et al. (2003) and Crockett et al. (2011). It was further observed that combined use of hydrocolloid(s) with surfactants in dough formulation did not have a significant $(P>0.01)$ impact on the moisture content of breads compared to the breads made without using surfactants (Pyler 1988).

While the moisture content of breads at the $24^{\text {th }} \mathrm{h}$ showed no major change compared to the $6^{\text {th }} \mathrm{h}$, their crumb softness quite significantly reduced. This reveals that the breads stale over time. The major factors that have an impact on the staling of bread include starch retro gradation, moisture content, protein content and quality of bread as well as ambient temperature (Bechtel 1955; Pomeranz and Shellenberger 1971; Pyler 1988). High staling values achieved in the study are not attributable to the moisture content of the breads in accordance with the data obtained from the moisture values but especially associated with the retro gradation of corn starch as well as protein content and quality that affect the rate and degree of the retro gradation process. As starch is used instead of flour in the study, starch is almost entirely composed of carbohydrates and its composition has practically no protein content (while wheat flour contains $10-15 \%$ protein), caused the quickly get stale of the bread samples, although they did not lose moisture.

It was observed that the crumb softness of breads usually vary in accordance with the volume yields of breads. It was also highlighted by Krog (1981) and Ozer (1998) that there is a linear relationship between the volume yield and crumb softness values of the breads.

Gluten free formulations for bread making are developed all around the world, using numerous non-cereal source materials. We applied corn starch as the main component in our formulation. Our finding can be generalized and applied for other formulations like rice flour based, manioc starch based, etc. products.

The impact of the hydrocolloids and their ratios and whether the surfactant was used on the volume yield, crumb-grain structure, NBC value, moisture content and penetro- 
meter values was found to be significant $(P<0.01)$, while their impact on crumbling was found to be insignificant $(P>0.01$; Table S4). HPMC gum was found to be more effective than the xanthan gum at any level of use in terms of bread volume yield. However, the cracks that were seen on the crust structure of breads became clear because of the increase of HPMC gum level in the additive formula. Xanthan gum was significantly superior to the HPMC gum in respect of the crumb-grain structure. Moisture content of the breads did not attain a level that may adversely affect their consumption.

The use of surfactants along with the gums improved the pore structure of the breads, while it did not have any impact on nor adversely affect other characteristics of the breads. Moisture contents, pore structures and thus NBC values of the breads made using the formulas where the gums were used together resulted in much higher values than the breads where the gums were used alone and there was not seen any clearly positive impact of the combination formulas on other measurements.

Considering all findings of the study together, it was concluded that high-quality gluten-free breads can be made, if both hydrocolloids were used in combination, that the combined use of $0.75 \%$ xanthan gum and $0.75 \%$ HPMC gum was useful by taking the personal observations into consideration and that the overall structural characteristics and taste of the bread made using the additive combination as specified above were close to the white bread.

\section{References}

AACCI 2000. Approved Methods of the American Association of Cereal Chemists International. Method 10-05.01, Method 10-10.03, Method 44-01.01. 10th ed. The Association. St. Paul, MN, USA.

Bechtel, W.G. 1955. A review of bread staling research. Tran. AACC 13:108-121.

Bell, D.A. 1990. Methylcellulose as a structure enhancer in bread baking. Cereal Food. World 35:1001-1006.

Birnbaum, H. 1978. Surfactants and shortenings in cake making. Bakers Dig. 2:28-38.

Ciclitira, P.J., Ellis, H.J., Lundin, K.E.A. 2005. Gluten free diet - what is toxic? Best Pract. Res. Cl. Ga. 19:359-371.

Crockett, R., Ie, P., Vodovotz, Y. 2011. How do xanthan and hydroxypropyl methylcellulose individually affect the physicochemical properties in a model gluten-free dough? J. Food Sci. 76:274-282.

Demirkesen, I., Kelkar, S., Campanella, O.H., Sumnu, G., Sahin, S., Okos, M. 2014. Characterization of structure of gluten-free breads by using X-ray microtomography. Food Hydrocolloids 36:37-44.

Ebeler, S.E., Walker, C.E. 1984. Effects of various sucrose fatty acid ester emulsifiers on high-ratio white layer cakes. J. Food Sci. 49:380-383, 388.

Farrell, R.J., Kelly, C.P. 2001. Diagnosis of celiac sprue. Am. J. Gastroenterol. 96:3237-3246.

Gallagher, E., Gormley, T.R., Arendt, E.K. 2003. Crust and crumb characteristics of gluten free breads. J. Food Eng. 56:153-161.

Gallagher, E., Gormley, T.R., Arendt, E.K. 2004. Recent advances in the formulation of gluten-free cerealbased products. Trends Food Sci. Tech. 15:143-152.

Gobbetti, M., Giuseppe Rizzello, C., Di Cagno, R., De Angelis, M. 2007. Sourdough lactobacilli and celiac disease. Food Microbiol. 24:187-196.

Gujral, H.S., Guardiola, I., Carbonell, J.V., Rosell, C.M. 2003. Effect of cyclodextrinase on dough rheology and bread quality from rice flour. J. Agr. Food Chem. 51:3814-3818.

Gul, H., Ozer, M.S., Dizlek, H. 2009. Improvement of the wheat and corn bran bread quality by using glucose oxidase and hexose oxidase. J. Food Quality 32:209-223.

Holtmeier, W., Caspary, W.F. 2006. Celiac disease. Orphanet J. Rare Dis. 1:1-8. 
International Food Information Council [IFIC] Foundation and United States Food and Drug Administration [FDA]. 2010. Food Ingredients and Colors. IFIC Foundation. Washington DC, USA. 8 p.

Katina, K., Arendt, E., Liukkonen, K.H., Autio, K., Flander, L., Poutanen, K. 2005. Potential of sourdough for healthier cereal products. Trends Food Sci. Tech. 16:104-112.

Krog, N. 1981. Theoretical aspects of surfactants in relation to their use in breadmaking. Cereal Chem. 58:158-164.

Lazaridou, A., Duta, D., Papageorgiou, M., Belc, N., Biliaderis, C.G. 2007. Effects of hydrocolloids on dough rheology and bread quality parameters in gluten-free formulations. J. Food Eng. 79:1033-1047.

López, A.C.B., Pereira, A.J.G., Junqueira, R.G. 2004. Flour mixture of rice flour, corn and cassava starch in the production of gluten-free white bread. Braz. Arch. Biol. Techn. 47:63-70.

Mahmoud, R.M., Yousif, E.I., Gadallah, M.G.E., Alawneh, A.R. 2013. Formulations and quality characterization of gluten-free Egyptian balady flat bread. Ann. Agr. Sci. 58:19-25.

Marco, C., Rosell, C.M. 2008. Functional and rheological properties of protein enriched gluten free composite flours. J. Food Eng. 88:94-103.

Neumann 1929. What temperatures are safe for drying grain? Muhle 66:1610-1611.

O’Neill, J. 2010. Gluten-free foods: trends, challenges, and solutions. Cereal Food World 55:220-223.

Ozer, M.S. 1998. Kepekli ekmeklerin bazı niteliklerinin incelenmesi ve kalitelerinin iyileştirilmesi olanakları (Determination of some characteristics of bran added breads and improvement of their qualities). Ph.D. Thesis. Cukurova University. Adana, Turkey. pp. 64-113. (in Turkish)

Ozer, M.S., Altan, A. 1995. Effect of using some additives on bread rolls quality. Gida 20:357-363.

Pomeranz, Y., Shellenberger, J.A. 1971. Bread Science and Technology. The Avi Publishing Company. Westport, Connecticut, USA, pp. 169-186.

Pyler, E.J. 1988. Baking Science and Technology. Sosland Publishing Company, Merriam, Kansas, USA, pp. 443-496, 815-842.

Rosell, C.M., Rojas, J.A., Barber, C.B. 2001. Influence of hydrocolloids on dough rheology and bread quality. Food Hydrocolloids 15:75-81.

Sciarini, S.L., Ribotta, D.P., León, E.A., Pérez, T.G. 2010. Influence of gluten-free flours and their mixtures on batter properties and bread quality. Food Bioprocess Tech. 3:577-585.

Shewry, P.R., Tatham, A.S., Lazzeri, P. 1997. Biotechnology of wheat quality. J. Sci. Food Agr. 73:397-406.

Shin, D.J., Kim, W., Kim, Y. 2013. Physicochemical and sensory properties of soy bread made with germinated, steamed, and roasted soy flour. Food Chem. 141:517-523.

Stauffer, C.E. 1990. Functional Additives for Bakery Foods. Chapman and Hall. London, UK.

Torbica, A., Hadnađev, M., Dapčević, T. 2010. Rheological, textural and sensory properties of gluten-free bread formulations based on rice and buckwheat flour. Food Hydrocolloids 24:626-632.

Toufeili, I., Dagher, S., Shadarevian, S., Noureddine, A., Sarakbi, M., Farran, M.T. 1994. Formulation of gluten-free pocket-type flat bread optimization of methylcellulose, gum arabic, and egg albumin level by response surface methodology. Cereal Chem. 71:594-601.

TSE 1987. TS 5000 Bread. Turkish Standards Institution, Ankara, Turkey.

Turabi, E., Sumnu, G., Sahin, S. 2008. Rheological properties and quality of rice cakes formulated with different gums and an emulsifier blend. Food Hydrocolloids 22:305-312.

Uluoz, M. 1965. Analytical Methods of Wheat, Flour and Bread. $1^{\text {st }}$ ed. Ege University Faculty of Agriculture Offset Facilities. Izmir, Turkey, $91 \mathrm{p}$.

United States Department of Agriculture Food Safety and Inspection Service 2015. U.S. Codex and Codex Alimentarius, Regulations and Policies. www.fsis.usda.gov. Accessed 02/09/2015.

Yaseen, E.I., Herald, T.J., Aramouni, F.M., Alavi, S. 2005. Rheological properties of selected gum solutions. Food Res. Int. 38:111-119. 


\section{Electronic Supplementary Material (ESM)}

Electronic Supplementary Material (ESM) associated with this article can be found at the website of CRC at http://www.akademiai.com/content/120427/

Electronic Supplementary Table S1. Ingredients used in the surfactant preparation and their amounts

Electronic Supplementary Table S2. Variable ingredients used in the research and their level of use on the basis of starch (\%)

Electronic Supplementary Table S3. Dallman crumb-grain (pore) scale (Uluoz 1965)

Electronic Supplementary Table S4. Average data for all measured values of gluten-free breads made using different combinations of additives

Electronic Supplementary Figure S1. The procedure steps followed for surfactant preparation in gel form to use in gluten-free bread making

Electronic Supplementary Figure S2. Processing steps applied in gluten-free bread making in the study 